DOI 10.21680/1517-7874.2019v21n1ID16126

\title{
INTERAÇÕES DE TELETANDEM INSTITUCIONAL NA PERSPECTIVA DIALÓGICA BAKHTINIANA
}

\section{INSTITUTIONAL TELETANDEM INTERACTIONS IN THE BAKHTINIAN DIALOGICAL PERSPECTIVE}

\author{
Maisa de Alcântara Zakir ${ }^{1}$ \\ Luciane de Paula ${ }^{2}$ \\ Universidade Estadual Paulista (UNESP)
}

\section{RESUMO}

Este trabalho é parte de um estudo de natureza etnográfica que integrou o projeto Teletandem e transculturalidade na interaşão on-line em linguas estrangeiras por webcam. O teletandem é um contexto telecolaborativo de aprendizagem de línguas estrangeiras, que, por meio de aplicativos de tecnologia VOIP (Voice Over Internet Protocol), promove o contato intercultural entre alunos brasileiros e alunos de diferentes instituições parceiras pelo mundo. Neste trabalho, desenvolvido em um pesquisa de pós-doutoramento, analisa-se um excerto de interação entre um aluno de uma universidade privada estadunidense e uma aluna de uma universidade pública brasileira. A transcrição é analisada na perspectiva dialógica fundamentada nos estudos bakhtinianos. Os resultados da análise evidenciam a constituição de sujeitos na relação eu-outro, por meio da dinâmica que os interagentes estabelecem no processo de realização do teletandem.

PALAVRAS-CHAVE: Aprendizagem de Línguas Estrangeiras. Teletandem. Análise Dialógica do Discurso.

\begin{abstract}
This paper is part of an ethnographic study that integrated the project "Teletandem and transculturality in online interactions in foreign languages by webcam". Teletandem is a telecollaborative context for learning foreign languages, which, through VOIP (Voice Over Internet Protocol) technology, promotes intercultural contact between Brazilian students and students from different partner institutions around the world. In this paper, developed in a postdoctoral research study, we have analyzed an excerpt of an interaction between a student of a private university in the United States and a student of a Brazilian public university. The transcription is analyzed under the dialogical perspective, grounded in the work of Bakhtin studies. The results of the analysis show the constitution of subjects in the self-other relationship, through the dynamics that participants establish throughout the teletandem process.

KEYWORDS: Foreign Language Learning. Teletandem. Dialogical Discourse Analysis.
\end{abstract}

\footnotetext{
1 Doutora em Estudos Linguísticos pelo PPGEL, UNESP-São José do Rio Preto, concluiu estágio de pósdoutorado com bolsa CAPES-PNPD no PPG em Linguística e Língua Portuguesa, UNESP-Araraquara. E-mail: maisa.zakir@unesp.br. Código ORCID 0000-0002-1792-3026.

2 Doutora em Linguística e Língua Portuguesa pelo PPGLLP, UNESP-Araraquara, com pós-doutorado pela Université François Rabelais - Tours, France. Professora da UNESP-Assis e do PPGLLP da UNESPAraraquara. Coordenadora do GED, Grupo de Estudos Discursivos. E-mail: lucianedepaula1@gmail.com. Código ORCID 0000-0003-1727-0376.
} 


\section{INTRODUÇÃO}

O contexto no qual este trabalho se insere envolve o uso de tecnologias da informação e comunicação no ensino e aprendizagem de línguas estrangeiras (LE). Dentre as modalidades que utilizam o computador como forma de diminuir distâncias geográficas e possibilitar o contato intercultural entre pessoas de diferentes localidades pelo mundo, pode-se destacar a telecolaboração.

De acordo com O'Dowd (2011, p. 342), a telecolaboração pode ser definida como a utilização de "ferramentas de comunicação online para reunir grupos de aprendizes de línguas em locais geograficamente distantes para desenvolver suas habilidades linguísticas e competência intercultural por meio de tarefas colaborativas e trabalho de projeto"’. A prática de teletandem tem tido grande importância no âmbito da telecolaboração, também entendida como "troca e interação online" (OIE, Online Interaction and Exchange, em inglês), conforme a expressão empregada por Dooly e O’Dowd (2012).

O teletandem é um contexto virtual síncrono e telecolaborativo de aprendizagem entre dois falantes nativos (ou proficientes) de diferentes línguas (TELLES, 2006; TELLES; VASSALLO, 2009). Em interações realizadas com recursos de voz, texto e imagens de webcam, por meio do Skype ou outros aplicativos de tecnologia VOIP (Voice Over Internet Protocol), os participantes trabalham colaborativamente com o objetivo de aprenderem a língua um do outro. Nas sessões, que geralmente têm duração de uma hora, o tempo é dividido em duas partes iguais, nas quais os parceiros interagem em uma língua de cada vez, ajudando o outro a aprender a sua língua. De acordo com as orientações que o projeto Teletandem apresenta, a língua de início de cada interação deve ser trocada, tendo em vista que a primeira parte da interação parece ser sempre mais produtiva (TELLES; VASSALLO, 2006).

Tal orientação sustenta-se pelo fato de que um dos princípios norteadores do teletandem é a reciprocidade, que indica que ambos os parceiros ${ }^{4}$ precisam ter a mesma possibilidade de aprendizagem nas interações. Os outros princípios do teletandem são a autonomia e o uso separado das línguas. Todos eles foram primeiramente atribuídos ao contexto de aprendizagem em tandem, descritos por Brammerts (1996). Surgido na Europa, devido ao fluxo de pessoas de diferentes países em muitos lugares, o tandem presencial não seria possível em grande parte do território brasileiro, principalmente em cidades pequenas, afastadas de grandes centros, que não têm a circulação massiva de pessoas estrangeiras que possam praticá-lo. Diante dessa constatação, o teletandem foi idealizado por Telles (2006) como um projeto de dimensão política e democrática, na medida em que possibilita a alunos universitários brasileiros tanto o acesso gratuito a diferentes línguas como o contato com alunos estrangeiros, sobretudo àqueles que não têm a oportunidade de realizar um intercâmbio no exterior.

Desde 2010, o projeto é intitulado Teletandem e transculturalidade e tem desenvolvido parcerias com as universidades estrangeiras na modalidade institucional (ARANHA; CAVALARI, 2014). Isso implicou a realização de sessões de teletandem envolvendo turmas inteiras de alunos de português como língua estrangeira e grupos de alunos brasileiros nos laboratórios das universidades participantes. Nas instituições

\footnotetext{
3 No original: “[...] online communication tools to bring together classes of language learners in geographically distant locations to develop their foreign language skills and intercultural competence through collaborative tasks and project work."

4 Entende-se, aqui, os parceiros de telecolaboração como sujeitos discursivos. A importância da fundamentação teórica bakhtiniana justifica-se pela centralidade do tandem na interação eu-outro, noção constitutiva de sujeito para o Círculo. As identidades socioculturais constroem-se na interação com outras sociedades (isto é, com a e por meio da alteridade) e o contato entre línguas coloca em jogo as identidades socioculturais, as quais são calcadas em experiências vividas.
} 
estrangeiras, grande parte dos grupos têm suas interações de teletandem incluídas no programa oficial dos cursos de graduação. Trata-se da modalidade de teletandem institucional integrado, em que as sessões são realizadas durante as aulas de português. No Brasil, a maioria das parcerias conta com a participação de alunos voluntários, que não realizam as interações durante as aulas de LE, o que configura a modalidade de teletandem institucional não-integrado (ARANHA; CAVALARI, 2014). Atualmente, os alunos são colocados em pares que, na maioria das vezes, se mantêm ao longo do semestre e realizam a interação, acompanhada pelo professor da turma, no caso das universidades estrangeiras, e pelo professor dos alunos, ou por um pesquisador do projeto, no caso da universidade brasileira (UB).

A institucionalização do teletandem possibilitou o desenvolvimento de parcerias de ensino e pesquisa entre universidades brasileiras e estrangeiras. Os dados analisados neste trabalho resultam de uma dessas parcerias em uma universidade estadunidense (doravante UE), de 2012. A proposta deste artigo é refletir acerca da perspectiva dialógica bakhtiniana, para analisar as interações de uma dupla de interagentes de teletandem, em suas dimensões linguística e translinguística.

As seções a seguir referem-se à fundamentação teórica, ao percurso metodológico e à análise das interações entre os participantes da pesquisa, Brendan e Sílvia ${ }^{5}$, respectivamente alunos da UE e da UB. As considerações finais revelam como a dinâmica das interações em teletandem impacta a constituição dos sujeitos por meio da relação eu-outro, conforme sustenta a perspectiva dialógica bakhtiniana.

\section{Fundamentação teórica}

O Círculo de Bakhtin, ao propor uma concepção de linguagem interativa/dialógica, que não pode ser pensada de modo apartado de seu conteúdo ideológico, impactou diferentes áreas do conhecimento. As ideias filosóficas do Círculo trouxeram para a linguística uma perspectiva calcada nas relações sociais e históricas, por meio das quais a linguagem se concretiza e carrega valores ideologicamente construídos.

O ensino e aprendizagem de LE é uma das áreas nas quais as ideias bakhtinianas tiveram impacto. Segundo Kramsch (2009), o interesse por Bakhtin entre os estudiosos da linguagem coincide com a percepção de que o ensino de línguas não precisa estar vinculado a teorias estruturalistas, que veem a língua como separadas de sua realidade.

Este trabalho fundamenta-se nos princípios teórico-metodológicos da Análise Dialógica do Discurso (ADD), calcada, sobretudo, na proposta de Bakhtin (2013) de criar uma disciplina chamada "Metalinguística" ou "Translinguística." Ao analisar as interações na construção da linguagem nas obras de Dostoiévski, Bakhtin constata que as relações dialógicas são impossíveis sob uma perspectiva rigorosamente linguística. Para ele,

A linguística conhece, evidentemente, a forma composicional do "discurso dialógico" e estuda as suas particularidades sintáticas léxicosemânticas. Mas ela as estuda como fenômenos puramente linguísticos, ou seja, no plano da língua, e não pode abordar, em

\footnotetext{
5 Os nomes dos participantes da pesquisa são fictícios e as instituições de que fazem parte são omitidas de modo a preservar sua identidade.

${ }^{6}$ Embora a tradução brasileira do livro Problemas da poética de Dostoiévski (BAKHTIN, 2013) utilize o termo metalinguística, adotado por Brait (2010), este trabalho adota o termo translinguística, em consonância com estudiosos brasileiros como Fiorin (2011) e Paula (2013). Fiorin (2011) justifica sua escolha pelos valores semânticos que envolvem metalinguística e explica que os prefixos meta (grego) e trans (latino) são equivalentes do ponto de vista do sistema. Paula (em conferências e cursos) justifica sua preferência pela não coincidência com a noção de função metalinguística, ou seja, por uma questão teórica.
} 
hipótese alguma, a especificidade das relações dialógicas entre as réplicas. Por isso, ao estudar o "discurso dialógico", a linguística deve aproveitar os resultados da metalinguística. (BAKHTIN, 2013, p. 209).

A translinguística tem por objeto "o exame das relações dialógicas entre os enunciados, seu modo de constituição real" (FIORIN, 2011, p. 33), pois leva em conta a historicidade do discurso. Do ponto de vista bakhtiniano, é por meio da linguagem que se constituem a sociedade e a cultura. O teletandem entremeia esses três conceitos. Assim, as interações podem ser analisadas em suas dimensões linguística e translinguística, conforme apontam pesquisas recentes (ZAKIR, 2015; MARINOTO, 2017). E a partir desta perspectiva que as interações entre os participantes/sujeitos de pesquisa, Brendan e Sílvia, são estudadas neste artigo.

A concepção de língua na qual este artigo se fundamenta considera que "[...] na prática viva da língua, a consciência lingüística dos sujeitos eu e outro nada tem a ver com um sistema abstrato de formas normativas, mas com a linguagem no sentido de conjunto dos contextos possíveis de uso de cada forma particular." (BAKHTIN/ VOLOCHINOV, 2004, p. 95). Nesse sentido, distanciamo-nos da concepção de linguagem da teoria saussureana, que constitui a maior expressão do chamado objetivismo abstrato. Para Bakhtin/Volochinov (2004, p. 96), "a separação da língua de seu conteúdo ideológico constitui um dos erros mais grosseiros do objetivismo abstrato".

Estabelecer a diferença entre essas concepções de linguagem é fundamental para esclarecer que uma análise calcada na perspectiva bakhtiniana se dá translinguisticamente, ultrapassa os limites da linguística e está, portanto, no nível discursivo.

Bakhtin (2013) confere a seu objeto de estudo uma dimensão extralinguística, ao explicar a proposição da translinguística:

[...] as relações dialógicas são extralingüísticas. Ao mesmo tempo, porém, não podem ser separadas do campo do discurso, ou seja, da língua enquanto fenômeno integral concreto. A linguagem só vive na comunicação dialógica daqueles que a usam. É precisamente essa comunicação dialógica que constitui o verdadeiro campo da vida da linguagem. Toda a vida da linguagem, seja qual for o seu campo de emprego (a linguagem cotidiana, a prática, a científica, a artística, etc.), está impregnada de relações dialógicas. Mas a Lingüística estuda a linguagem propriamente dita com sua lógica específica na sua generalidade, como algo que torna possível a comunicação dialógica, pois ela abstrai conseqüentemente as relações propriamente dialógicas. Essas relações se situam no campo do discurso, pois este é por natureza dialógico e, por isto, tais relações devem ser estudadas pela Metalingüística, que ultrapassa os limites da Lingüística e possui objeto autônomo e metas próprias. (BAKHTIN, 2013, p. 209).

Ao discorrer sobre as categorias de análise em Bakhtin, Fiorin (2011, p. 34) esclarece que "qualquer análise linguística pode ser utilizada como base de uma análise translinguística [...] Assim, numa análise translinguística, é preciso analisar as significações do texto, para, a partir daí, examinar as relações com o que está fora dele."

De acordo com Brait (2010), o embasamento da teoria dialógica postula

a indissolúvel relação existente entre língua, linguagens, história e sujeitos que instaura os estudos da linguagem como lugares de produção de conhecimento de forma comprometida, responsável, e não apenas como procedimento submetido a teorias e metodologias dominantes em determinadas épocas. Mais ainda, esse embasamento 
constitutivo diz respeito a uma concepção de linguagem, de construção e produção de sentidos necessariamente apoiadas nas relações discursivas empreendidas por sujeitos historicamente situados. (BRAIT, 2010, p. 10).

A historicidade e o dialogismo são constitutivos do discurso, como visto anteriormente na definição de Bakhtin (2013). A esse respeito, Fiorin (2011) assevera que

a palavra do outro é condição necessária para a existência de qualquer discurso, sob um discurso há outro discurso. Essas duas vozes não precisam estar marcadas no fio do discurso, elas são apreendidas pelo nosso conhecimento dos diferentes discursos que circulam numa dada época numa determinada formação social. (FIORIN, 2011, p. 40).

As pesquisas em teletandem que têm se baseado na abordagem translinguística de análise de dados (ZAKIR, 2015, MARINOTO, 2017) evidenciam que essa perspectiva teórico-metodológica possibilita uma compreensão da complexidade que constitui as interações online em LE entre os parceiros de teletandem.

\section{Percurso metodológico}

As reflexões apresentadas neste artigo são pautadas em uma perspectiva qualitativa. Há uma preocupação em se compreender o contexto no qual ela acontece e a qualidade dos fenômenos observados. Metodologicamente, este artigo fundamenta-se no entendimento de Amorim (2004) acerca da questão da alteridade, essencial no trabalho do pesquisador em Ciências Humanas. Estas, por sua vez, são vistas como ciências do texto/discurso (AMORIM, 2010; PAULA, 2013), na medida em que produzir textos é o que constitui, nos sujeitos, o caráter fundamentalmente humano. Para Amorim (2010),

Pesquisador e sujeito pesquisado são ambos produtores de texto, o que confere às Ciências Humanas um caráter dialógico. Uma primeira consequência disto é que o texto do pesquisador não deve emudecer o texto do pesquisado, deve restituir as condições de enunciação e de circulação que lhe conferem as múltiplas possibilidades de sentido. Mas o texto do pesquisado não pode fazer desaparecer o texto do pesquisador, como se este se eximisse de qualquer afirmação que se distinga do que diz o pesquisado. O fundamental é que a pesquisa não realize nenhum tipo de fusão dos dois pontos de vista, mas que mantenha o caráter de diálogo, revelando sempre as diferenças e a tensão entre elas. (AMORIM, 2010, p. 98)

Os participantes do estudo não são compreendidos como objetos, mas como sujeitos de pesquisa que, na concepção bakhtiniana, constiuem-se na relação eu-outro (BAKHTIN, 2006; 2010). Especificamente no contexto de teletandem, no qual dois interagentes de nacionalidades diferentes comunicam-se com o propósito de colaborarem para que um ajude o outro a aprender sua língua materna (ou de proficiência), a relação de parceria e reciprocidade entre os sujeitos é o que permeia o ensino-aprendizagem entre eles. Cada qual posiciona-se como sujeito sócio-históricocultural que, ao falar em determinada língua traz, com ela/por meio dela, sua noção da cultura que essa determinada língua expressa para ele. $\mathrm{Na}$ análise do corpus de pesquisa, são consideradas a dimensão espaço-temporal das interações, a dinâmica estabelecida pelos interagentes ao longo do processo de teletandem, bem como as vozes sociais que entram em embate na cadeia discursiva, pelo contato entre línguas proporcionado pelo 
contexto telecolaborativo em questão. Todos esses aspectos são essenciais para o êxito da telecolaboração.

Ainda que marcado por um tempo-espaço delimitados e com regras específicas para a interação, o teletandem revela, de maneira ímpar, a noção bakhtiniana de linguagem interativa e o diálogo necessita de sujeitos que representem suas culturas. Cada um dos parceiros/sujeitos da interação representa, com seu discurso (a escolha temática, o posicionamento diante de determinado tema etc.), vozes sociais acerca daquele conteúdo, explorado pela forma composicional específica do teletandem, com o estilo de cada agente.

O olhar translinguístico e dialógico para as interações de teletandem, foco da análise apresentada neste artigo, implica considerar as "especificidades discursivas constitutivas de situações em que a linguagem e determinadas atividades se interpenetram e interdefinem, e do compromisso ético do pesquisador com o objeto, que, dessa perspectiva, é um sujeito histórico." (BRAIT, 2010, p. 29). No caso do estudo aqui reportado, é analisado um excerto de interação entre o aluno estadunidense, Brendan, e a aluna brasileira, Sílvia, que realizaram dez sessões de teletandem ao longo do primeiro semestre de 2012.

A coleta de dados da pesquisa foi realizada por uma das autoras deste artigo e constituiu parte do corpus utilizado por pesquisadores do projeto Teletandem, que enfocaram diferentes perspectivas em seus estudos (ZAKIR, 2015; FRANCO, 2016; MARINOTO, 2107; SOUZA, 2017). Das dez interações realizadas entre o grupo composto por alunos das instituições brasileira e estadunidense, cinco foram gravadas e transcritas para fins de pesquisa. $\mathrm{Na}$ análise apresentada na seção a seguir, demonstra-se como a dinâmica da interação constrói a relação entre os parceiros/sujeitos e os constitui no jogo discursivo engendrado no processo de comunicação em teletandem.

\section{Análise das interações em teletandem da dupla Brendan e Sílvia}

As interações de teletandem constituem um contexto profícuo de pesquisa em aprendizagem de LE na medida em que consistem em um processo de comunicação autêntica entre dois sujeitos situados historicamente, em uma dada dimensão espaçotemporal, que estabelecem contato para aprenderem a língua um do outro. É no próprio desenvolvimento desse processo comunicativo que a língua se materializa a partir da dinâmica estabelecida entre os interagentes/sujeitos. Como visto na introdução deste artigo, tal materialização ocorre por meio dos princípios de autonomia, reciprocidade e uso separado de línguas, que orientam a aprendizagem em tandem (BRAMMERTS, 1996) e teletandem (VASSALLO; TELLES, 2006).

Como interação, não se entende apenas a troca linguística, mas a discursiva, constituída também pela cultura, a história e as regras e vozes sociais - não como extra, mas como parte integrante da noção de língua -, conforme evidencia a ideia de translinguística já mencionada.

Como recorte, este artigo apresenta um longo excerto de interação realizada no dia 09 de abril de 2012, logo após o feriado de Páscoa, entre os participantes/sujeitos da pesquisa, Brendan e Sílvia, que se alteram entre eu-outro na interação, colocada de maneira viva, em jogo histórico-social. Como forma de se entender a dinâmica de interações e os temas tratados, foram sintetizadas as sessões transcritas dessa dupla.

09 de abril de 2012: A interação tem início em português e o principal assunto é o feriado de Páscoa, que, no ano de 2012, coincidiu com a páscoa judaica (Passover, em inglês). Há negociação de significados para esclarecimento de uso da LE. Os interagentes mantêm o uso separado das línguas a maior parte do tempo e são observadas 
interferências do espanhol em alguns momentos na fala de Brendan. Ambos parecem recorrer a dicionários online, a ferramentas de busca e ao chat quando têm dúvidas.

11 de abril de 2012: A interação começa em inglês, mas há momentos de code switching em ambos os turnos. Os sujeitos falam sobre gírias e expressões idiomáticas, utilizam a internet para encontrar exemplos e o chat para facilitar a compreensão do parceiro.

16 de abril de 2012: Brendan e Sílvia começam a interação em português e conversam sobre as atividades dela e os plano dele de mudança de universidade. Nessa interação, eles voltam a compartilhar gírias e expressões em inglês e também utilizam recursos da internet para auxiliar a compreensão.

18 de abril de 2012: A interação começa em inglês, mas são observados muitos momentos de code switching. No turno em inglês, Brendan ensina algumas expressões para Sílvia e, no turno em português, eles trocam vocabulário sobre vestimentas. Os turnos de fala da brasileira são mais longos em português. Eles conversam, ainda, sobre uma festa para a qual Sílvia vai com as amigas e sobre seus respectivos trabalhos da faculdade. Ao final da interação, eles planejam falar sobre filmes na sessão seguinte de teletandem.

23 de abril de 2012: A última interação tem início em português e os alunos são orientados a fazerem uma avaliação sobre a aprendizagem em teletandem. Eles falam sobre o que haviam feito no fim de semana e sobre alguns jogos no estilo do futebol americano. A frequência de respostas curtas de Brendan é recorrente e, em alguns momentos, não fica evidente se houve realmente o entendimento da mensagem ou se a concordância é um recurso para manter a interação se desenvolvendo.

As informações sobre as interações de teletandem entre Brendan e Sílvia estão sintetizadas no quadro a seguir:

\begin{tabular}{|c|c|c|c|c|c|}
\hline $\begin{array}{l}\text { Brendan e } \\
\text { Sílvia }\end{array}$ & $09 / 04 / 2012$ & $11 / 04 / 2012$ & $16 / 04 / 2012$ & $18 / 04 / 2012$ & $23 / 04 / 2012$ \\
\hline $\begin{array}{c}\text { Duração das } \\
\text { sessões/ }\end{array}$ & $32^{\prime} 50^{\prime \prime}$ & $45^{\prime} 48^{\prime \prime}$ & $45^{\prime} 30$ & 49’53" & $46^{\prime} 45^{\prime \prime}$ \\
\hline $\begin{array}{c}\mathrm{n}^{\mathbf{o}} \text { linhas das } \\
\text { transcrições }\end{array}$ & 497 & 409 linhas & 367 linhas & 668 linhas & 581 linhas \\
\hline $\begin{array}{l}\text { Síntese de } \\
\text { assuntos }\end{array}$ & $\begin{array}{c}\text { - Feriado de } \\
\text { Páscoa e Pásscoa } \\
\text { judaica (Passover); } \\
\text { - Comidas. }\end{array}$ & $\begin{array}{c}\text { - Gírias e } \\
\text { expressões } \\
\text { idiomáticas. }\end{array}$ & $\begin{array}{c}\text { - Planos e } \\
\text { atividades dos } \\
\text { interagentes; } \\
\text { - Gírias e } \\
\text { expressões } \\
\text { idiomáticas. }\end{array}$ & $\begin{array}{l}\text { - Expressões } \\
\text { em inglês; } \\
\text { - Vestimentas; } \\
\text { - Festa; } \\
\text { - Trabalhos da } \\
\text { faculdade }\end{array}$ & $\begin{array}{c}\text { - Festa; } \\
\text { - Esportes } \\
\text { (futebol, } \\
\text { beisebol, futebol } \\
\text { americano); } \\
\text { - jogos/ } \\
\text { brincadeiras. }\end{array}$ \\
\hline
\end{tabular}

Quadro 1: Síntese das interações de teletandem entre Brendan e Sílvia .

Com relação à dinâmica das interações, pode-se afirmar que a dupla Brendan e Sílvia foi uma das mais assíduas do grupo que teve os dados coletados para a pesquisa (ZAKIR, 2015; SOUZA, 2016). Brendan e Sílvia seguiram a orientação de mudar a língua de início em cada uma das sessões, ainda que tenham sido observados muitos momentos de code switching. As interações têm como assuntos predominantes as gírias e expressões idiomáticas, as atividades diárias e as preferências dos dois alunos com relação a filmes e livros. No excerto a seguir, Brendan e Sílvia conversam sobre o que haviam feito no final de semana que precedeu a interação do dia 09 de abril de 2012. 
B: As memórias para, na realidade, no são, [?]. Esse fim de semana eu visitei ah meus avós

$\mathrm{S}: \mathrm{Ai}$, que lindo

B: É, e agora estou um pouco nervoso, porque eu deixei minhas chaves lá.

S: Nossa

B: Então a porta de minha, de mi quarto está

S: Trancada

B: Sim, agora

S: Nossa! Mas você não mora sozinho?

B: No, eu moro aqui, na faculdade.

S: Mas é, você, é república, você divide com alguém?

B: Sim, eu tenho companheiro, mas ele não está, porque ele também

S: Foi pra casa?

B: Exato. E ele volta hoje, mas,

S: Enquanto isso você está pra fora?

B: Aham

S: Oh my God, ai meu Deus! Mas tem que tentar ficar calmo, porque não adianta ficar nervoso

B: Uhum

S: É, tem, se, ele vai chegar só à tarde?

B: Não, um neto, de, dos amigos de meus avós, querem ver mi, a universidade. Entao está visitándolo hoje e meus avós os deixou minhas chaves.

S: Nossa!

B: E nosotros vamos a encontrarnos. E ele me va a dar.

S: Ai, que legal!

B: Em como dos horas. Mas, hasta, hasta

S: Até lá...

B: Até lá, ah, toy nervoso

S: Oh my God,

B: Yeah, yeah.

S: Mas já está resolvido, não fique nervoso.

B: Não queria assistir à aula, não queria sair.

S: Entendi, porque você quer resolver logo, eu imagino, hahaha. Eu também sou muito ansiosa, nossa!

B: Trouxe minha laptop comigo.

S: Seu o quê? Seu chocolate? [Brendan digita algo e envia no chat]

B: Não, não.

S: Hahaha [provavelmente lendo a palavra "laptop" no chat]

B: No, ah, computador.

S: Ah, okay. Seu computador. Você trouxe seu computa...

B: Não tenho que usarlo, mas eu, eu, ah, quise terlo comigo.

S: Ah, aham

B: É

S: Que bom então. Dá pra vc tentar se distrair com ele

B: Yeah.

S: Enquanto isso

B: Também eu viu minha, meus primos. Para e celebramos a Passover?

S: Páscoa.

B: No, no, no, no, no Páscoa.

S: Passover? I don't know. Não sei.

B: É um ferriado "rudeaco". Ju, "rudeaco", judaico, judaico.

S: Ah, judaico?

B: É

S: Ah:::

B: E

S: Han, só que diferente de Páscoa?

B: Ah, muito. Não tem nada que fazer com Páscoa.

S: Ah::

B: Tem que fazer com, ah, um cuento de Moses, não sei se você sabe. 


\section{S: Como?}

B: Ah

S: Musis?

B: Como?

S: Com músicas?

B: Sim, como de[...] Ah, sim, sim. Tem [digita e eles ficam em silêncio...]

S: Moses?

B: É

S: Isso é o quê? Um...

B: Homem.

S: Homem?

B: Uhum. É nome

S: Hã, nome?

B: Uhum, nome de um homem, de um homem.

S: De um homem?

B: Aham, sim.

S: Mas ele representa alguma coisa pra...

B: Ele representa basicamente a re, religión? Ele ah, ele, ha, no sei, ah [procura algo na internet]. Ele, não sei, rsrs [balbucia algo]

S: No problem

B: Ele levar todos os "rudeos" fuera, fora de, ah, "Errito",

S: Ah:::::,

B: Egito.

S: Então eu sei, agora sim eu entendi quem que é

$\mathrm{B}: \mathrm{Ah}$

S: Oh God, ahn, Moisés.

B: Ahn, Moisés, Moisés

S: Ele, sim, escreve assim ó, in Portuguese [escrevendo]

B: Aham. Ele, eu queria dizer que ele, ah, mas não soube como dizer que ele levou todos os ah para ah fora de "Errito".

S: Sim

B: É, então.

S: Ele levou a população pro, os escravos, né, do Egito

B: Uhum

S: pra fora do Egito

B: uhum

S: e abriu o Mar Vermelho, não é?

B: Aham

S: Pra dar passagem

B: Uhum

S: Pra, eles foram em busca de uma terra nova, né?

B: Hum

S: Pra se libertarem, né?

B: Uhum

S: Da escravidão, da, do Egito,

B: Tem um,

S: E aí,

B: Tem uma

S: A terra prometida por Deus

B: Aham

S: Sim?

B: Exato. Tem um filme muito popular, que gana muitos prêmios, que se chama "the ten" [digita], muito famoso, com um pouco, dejô [?], 50, ahn, de 1954, ahn, e temos um, temos um ritual que cada ano, ah, minha família, ahn, assistimos essa filme na televisão.

S: Nossa!

B: É 
S: E esse filme...

B: É um

S: Esse filme é sobre Moisés?

B: Sim, a, a história é muito lonjo, como quatro horas.

S: Nossa!

B: Por DVD, tem dos discos.

S: Nossa

B: É. É muito legal porque pode ver a roupa, eh, ah, it's really cool.

S: Uhum

B: Ah, uh, muito famosa.

S: Nossa! Que legal!

B: É, [balbucia]

S: E

B: E também eu, uh, os, ah, os masters de golfe estão ocurrendo e meu avô, ele é um grand, fan, fã, fan?

S: Como?

B: Aficionado.

S: Aficionário? Funcionário?

B: Afi, um ah, suporte? De golfe

S: Apoio? Apoia?

B: Ah

S: Ele é... suporte é dar apoio, ele seria, é, como se diz? Gerente, ou

B: Ele é um fã de golfe.

S: Ah, okay, fã?

B: E isso está ocorrendo agora é nosotros assistimos muito ah, muitos jogos. Não como jogos, mas, muito tempo.

[mediadora ao fundo: já trocaram?]

B: Ainda não

S: [pode trocar de língua]

B: Oh, trocamos a língua.

S: Okay

B: Ah, we were watching the Golf Masters. It's, it's a tournement, um turn, ah, sabe? Um tournement. É um, ah, what the heck [digitando], my mouse, é um torneio, the t [?], ah, really, like, really a big tournement that's going on right now. And much of where it is (?). But that's we were watching, a lot of people watch that, especially, ah, where my grandparents live, because they live in a, in a country club, sabe? Ah

S: Okay, I know

B: E, and, all, what people like to do there, is that they like to play tennis, they like to play golf, and when, like a big tournement is on, everybody goes grazy, and they all watch it, they all love it, so,

S: Hum,

B: So we did.

S: cool

B: Ah, I wish, we didn't get to play golf, we usually do, but I didn't get to play.

S: Hum

B: We were kind of busy with stuff. Ah. That's

S: Cool I, I would like

B: Aham

S: Han play

B: Aham

S: Tenis

B: Yeah, uhum, yeah, that's a lof of fun

S: Yes

B: Are there courts at your school?

S: I courts? What?

B: Are there, ah, tenis courts?

$\mathrm{S}$ : Tenis courts? Yes 
B: Ah, there are, ok, I expected already, there are, yeah, we have here too. But, I, I har, I don't really play that much here. I haven't played actually once here. Just, I don't know, too busy, I guess.

S: Rsrs, yes.

B: It's a lof of fun though.

S: Yes. I am busy, I am studying every day.

O excerto acima tem turnos em português e em inglês e em ambos observa-se que há momentos de mal entendidos na interação (SOUZA, 2016), em que os sujeitos trocam de papéis (eu-outro), em franco discurso direto. Um dos mal entendidos ocorre em relação à Páscoa judaica (Pessach em hebraico e Passover em inglês), cujo significado a interagente brasileira desconhece. A interação se desenvolve de modo que Brendan assume o papel de eu e the explica que a celebração religiosa está ligada à libertação dos “judeus” do Egito por Moisés.

A negociação de sentidos estabelecida entre as linhas 142 e 168 evidencia que Sílvia, no caso, no lugar do outro (o você/tu do discurso), entende que, na linha 163, Brendan havia se referido a Moisés ("Ele levar todos os "rudeos" fuera, fora de, ah, "Errito"), quando ela responde na linha 166: "Então eu sei, agora sim eu entendi quem que é". Brendan pronuncia o "j” de “judeus" e o "g" de "Egito" como em espanhol, [hud'eo] e [eh'ito]).

Ainda que Sílvia não tenha a mesma religião de Brendan, o Judaísmo, a interagente brasileira é familiarizada com a história de Moisés, um dos profetas mais importantes também do Cristianismo, além de ser reconhecido pelo Islamismo e por outras religiões. A interação entre eles demonstra que Brendan celebra a Páscoa judaica e que se refere ao povo libertado por Moisés como "judeus" (denominação que se deu em outro momento histórico) e não como "hebreus" em busca da, então, "Terra Prometida" por Deus (fato mencionado por Sílvia na linha 191). Ainda assim, é justamente nesse turno que Sílvia identifica a história do profeta. Isso porque Moisés, Egito e Mar Vermelho não são tomadas como palavras isoladas, mas como signos ideológicos (BAKHTIN/ VOLOCHINOV, 2004), que constituem uma memória partilhada por Sílvia e a fazem não só entender a referência feita por Brendan, mas também demonstrar que conhece a história contada no Antigo Testamento (o que se explicita quando se refere ao povo libertado por Moisés como escravos, na linhas 175 e 187). Isso evidencia a força do discurso religioso, sobretudo quando se trata de um personagem reconhecido como profeta em várias religiões. A interação, mais do que troca linguística, constitui-se como diálogo sociocultural, com trocas de referências históricas, axiologias, posicionamentos etc. Trata-se, portanto, de língua viva.

Num jogo de forças opostas ao discurso religioso está o da ciência, que indica que não há provas históricas ou arqueológicas de que os hebreus eram escravos nesse período do Egito Antigo, o que leva ao questionamento da existência histórica e/ou dos feitos de Moisés. A própria origem dos israelitas é questionada pela ciência, com os indícios de que tenham surgido na Palestina e não no Egito, conforme diz o texto bíblico. ${ }^{7}$ Como se sabe, há muitos desdobramentos religiosos, territoriais, econômicos e políticos a partir da saga de um "povo guiado por Deus em busca da terra prometida". Na interação entre Brendan e Sílvia, no entanto, não há essa discussão, uma vez que o estadunidense retoma a saga de Moisés apenas para explicar o significado da celebração do Passover. Mesmo assim, em uma perspectiva translinguística, os sentidos são produzidos dialógica e interdiscursivamente (BAKHTIN, 2013; FIORIN, 2011) e, portanto, não é possível pensar essa interação sem situá-la na esfera de que faz parte. A partir da explicação de Brendan, ambos se posicionam historicamente a partir da perspectiva religiosa e a diferença ocorre ao significado que atribuem a ela: para Sílvia, trata-se de uma passagem do Antigo Testamento e, para Brendan, representa uma das principais celebrações do judaísmo,

\footnotetext{
${ }^{7}$ Sites consultados: $<\underline{\text { https: / } / \text { www.terra.com.br/noticias/ciencia/o-que-a-ciencia-diz-sobre-moises-as-dez-pragas-o- }}$ exodo-e-a-travessia-do-mar-vermelho,0c520582c833ed1a1ff70ef29ef0f112hkiyit8p.html>;

$<$ http://g1.globo.com/Noticias/0,,MUL418821-9982,00-

MOISES+PODE+NAO+TER+EXISTIDO+SUGERE+PESQUISA+ARQUEOLOGICA.html>;

$<$ https://super.abril.com.br/historia/os-dez-mandamentos-a-verdadeira-historia-de-moises/>. Acesso em: 17 maio 2018.
} 
como evidenciado nas linhas 195 e 196 (“[...] temos um, temos um ritual que cada ano, ah, minha família, ahn, assistimos essa filme [sobre Moisés] na televisão.”). Trata-se de uma comemoração tradicional celebrada pela família de Brendan porque parte de sua história religiosa.

Ao explicar para Sílvia que Passover é muito diferente e não tem nada a ver (ele usa "nada a 'fazer"', provavelmente devido à tradução literal do verbo 'do' que compõe a expressão em inglês) com a Páscoa (linha 140), pode ser que Brendan desconheça a relação entre a passagem de Moisés pelo Mar Vermelho e a celebração da Páscoa cristã, que também representa uma passagem (de Cristo, com sentido mais metafísico, da morte para a vida). É possível, ainda, que, no jogo da interação, o objetivo dele seja, de fato, marcar as diferenças e não as proximidades, que, apesar de negadas e/ou desconhecidas por Brendan, existem entre ambas as celebrações:

a Páscoa cristã recebeu o nome da comemoração judaica porque a Paixão de Cristo aconteceu no início do Pessach - a festa judaica dura sete dias em Israel e oito em outros lugares. A cerimônia conhecida como Última Ceia teria sido um Seder, o tradicional jantar realizado na véspera do início da Páscoa judaica. (RAMOS, 2004).

Seja como for, as referências culturais ficam evidentes na interação entre os sujeitos, que se colocam de acordo com suas axiologias sócio-histórico-culturais. Um olhar translinguístico para os enunciados implica a análise das relações dialógicas na construção da linguagem, que são, de acordo com Bakhtin (2013), impossíveis sob uma perspectiva rigorosamente linguística. Os sentidos trazidos para a análise da interação entre Brendan e Sílvia extrapolam essa perspectiva. Ao contrário do que certas leituras da obra de Bakhtin fazem crer, o filósofo russo não nega a existência do sistema da língua e não condena seu estudo; propõe a translinguística porque se volta ao funcionamento real da linguagem (FIORIN, 2011). A proposta de Bakhtin considera que

A linguística conhece, evidentemente, a forma composicional do "discurso dialógico" e estuda as suas particularidades sintáticas léxico-semânticas. Mas ela as estuda como fenômenos puramente linguísticos, ou seja, no plano da língua, e não pode abordar, em hipótese alguma, a especificidade das relações dialógicas entre as réplicas. Por isso, ao estudar o "discurso dialógico", a linguística deve aproveitar os resultados da metalinguística. (BAKHTIN, 2013, p. 209).

Os conhecimentos partilhados pelos sujeitos acerca dos aspectos que envolvem a celebração da Páscoa cristã e judaica (como explicado por Brendan) são mobilizados para que eles consigam resolver o problema do mal entendido quando Brendan menciona o nome Moses (pronunciando-o, na linha 142, e mandando-o por escrito, na linha 148, para Sílvia) e Silvia só entende de quem se trata quando relaciona a expressão à informação de que esse homem havia levado os "judeus" para fora do Egito. É a referência que confere sentido ao linguístico e estudar língua significa considerar esse processo como um todo (elo na cadeia e ato singular). Afinal, a compreensão é construída por toda a corrente discursiva precedente e sucessora - como o que está nas linhas 157 (“é um homem”) e 160 (“Ele representa basicamente a re, religión”).

A linha 212 marca uma mudança de assunto: quando Brendan conta a Sílvia que seu avô é um grande fá de golfe e, como estava ocorrendo um campeonato desse esporte, eles haviam assistido a várias partidas no fim de semana. Também nesse trecho observa-se a negociação de sentidos entre os dois, uma vez que Sílvia não entende o significado de "aficionado" (linha 215), usado por Brendan para se referir a "fã". Esse mal entendido é resolvido na linha 222.

Em seguida eles trocam de língua de interação e começam a conversar em inglês. $O$ estadunidense explica à brasileira que o torneio de golfe é um acontecimento importante e que reúne as pessoas para assistir aos jogos e torcer. Essa atividade é ressaltada como ainda mais importante, especialmente no lugar onde os avós de Brendan moram. Ao ser perguntada se sabia 
o que era um country club, Sílvia responde afirmativamente. Brendan continua dizendo que as pessoas que moram nesse lugar gostam de jogar tênis e golfe, dois esportes altamente elitizados, assim como o lugar onde seus avós moram. No Brasil, seria o equivalente a um condomínio fechado, com área verde, quadras de tênis, campos de golfe, piscinas, entre outras opções de lazer. Trata-se de um contexto diferente da realidade da maioria dos brasileiros e destinado a uma parcela muito restrita da população, que detém a maior parte da renda produzida no país.

Em uma perspectiva translinguística, esse trecho revela o lugar social de onde fala o sujeito estadunidense. Estão no jogo da interação as vozes sociais de um sujeito do sexo masculino, que tem uma condição social privilegiada, que pratica e assiste a esportes elitizados (tênis e golfe) e frequenta lugares em que essas práticas sociais são comuns. Há, em contraste, as vozes sociais que constituem a parceira brasileira, que vive uma realidade diferente $\mathrm{da}$ de Brendan. Há uma questão de supremacia e inferioridade cultural e genérica marcada na interação. Brendan, o homem da dupla, é estadunidense. Mesmo com sua mistura do português com o espanhol, ele se coloca em posição dominante na interação. Ele fala mais, explica, tem menos medo de perguntar e experimenta mais a língua. Enquanto Sílvia, a mulher da dupla, brasileira, fala menos, coloca-se em posição de concordância mesmo quando hesita ou confirma informações que não correspondem à realidade vivida ou de seu país. Isso denota uma hierarquia genérica e cultural: a superioridade estadunidense evidencia-se com o domínio machista sobre a síndrome tupiniquim brasileira, de país de exploração, submisso à cultura do outro, considerado desenvolvido. A postura de Sílvia reproduz essa axiologia - por sua cordialidade em se colocar como o outro (tu/você) da interação na maior parte do tempo. Dobrada a questão da cultura com a do gênero dos sujeitos e suas posturas axiológicas, explicita-se essa valoração no todo da enunciação analisada, tomada como jogo vivo de língua (social).

Os turnos de Sílvia em inglês são curtos e isso pode ser uma evidência de pouca proficiência na compreensão oral da língua, assim como Brendan também tem dificuldades com o português. Ainda que Sílvia responda afirmativamente à pergunta de Brendan indicando que sabe o que é um country club, ela o faz de outro lugar, não pelas mesmas práticas sociais de Brendan. Isso é evidenciado quando Sílvia indica que gostaria de jogar tênis. Para além de analisar sua resposta, que divide a oração em três partes (linhas 245, 247 e 249), evidenciando a transposição da sintaxe do português (que permite a compreensão de sentidos mesmo sem o complemento) para o inglês, a perspectiva translinguística possibilita um olhar para a complexidade das relações sociais materializadas por meio da linguagem. Nesse sentido, o embasamento constitutivo da teoria dialógica do discurso, segundo Brait (2010, p. 10), "diz respeito a uma concepção de linguagem, de construção e produção de sentidos necessariamente apoiadas nas relações discursivas empreendidas por sujeitos historicamente situados."

Ao final do excerto, Brendan pergunta a Sílvia se há quadras de tênis na faculdade dela. A brasileira hesita, ele repete a pergunta e ela responde que há. Brendan diz que já esperava que houvesse e conta a Sílvia que na sua faculdade também há, mas que não joga lá por estar ocupado. Silvia diz que está ocupada, estudando todos os dias. Esse trecho parece corroborar que os momentos em que Sílvia responde afirmativamente a algo não necessariamente revelam que a resposta correspondeu à pergunta, mas que ela quer manter o fluxo da interação. A UB, onde Sílvia estuda, tem uma infraestrutura bastante diferente da UE e não há quadras de tênis, como ela afirmou. A resposta de Brendan na linha 256 revela sua expectativa, uma vez que a referência dele é outra (de alguém que estuda em uma universidade privada estadunidense, que conta com uma estrutura de apoio às mais diversas práticas esportivas), ao contrário do contexto de Sílvia.

Enfim, ao se empreender uma análise translinguística dos enunciados, pode-se entender o quanto a interação discursiva constitui o ensino-aprendizagem de língua, uma vez que esta não é apenas sistema, mas também cultura. Por isso, são identificadas, na interação analisada, algumas vozes sociais por meio das quais o discurso se constitui com o sujeito, (re)compondo-se o tempo todo no próprio processo interativo com o outro (BAKHTIN, 2006; 2010), como jogo vivo de linguagem em funcionamento - no caso, nos dois idiomas utilizados. 


\section{CONSIDERAÇÕES FINAIS}

Neste artigo, foi analisado um excerto de interação online entre um aluno estadunidense e uma aluna brasileira, que realizaram sua parceria telecolaborativa no contexto de institucionalização do projeto Teletandem e transculturalidade (TELLES, 2011). A análise evidenciou que a perspectiva translinguística possibilita entender o processo de aprendizagem de uma língua estrangeira no jogo da interação, em um contexto de comunicação autêntica entre dois sujeitos que se constituem na relação eu-outro, engajados telecolaborativamente, em troca sóciohistórico-cultural.

As questões linguísticas, sociais e ideológicas, constitutivas dos atos de linguagem e analisadas no excerto da interação entre Brendan e Sílvia, revelam que um se constitui na relação que estabelece com o outro e na dinâmica própria que estabelecem nas interações em teletandem, carregando, na língua, em ato, vozes sociais e culturais que constituem os sujeitos em diálogo.

Nesse sentido, pode-se considerar que, no embate discursivo que necessariamente se imprime no contato intercultural entre dois sujeitos situados historicamente, o processo de aprendizagem de LE (ousa-se dizer que de LM - Língua Materna - o processo seja semelhante) transcende a dimensão linguística, entendida como estrutura. Afinal, ele se realiza no jogo discursivo, que engendra novas possibilidades de inserção da tecnologia como forma de enriquecer o contexto de aula de LE, quebra barreiras físicas e coloca os sujeitos em contato com o mundo (as sociedades e culturas), por meio da língua viva, em uso.

\section{REFERÊNCIAS}

AMORIM, M. O pesquisador e seu outro: Bakhtin nas ciências humanas. São Paulo: Musa Editora, 2004.

AMORIM, M. Cronotopo e exotopia. In: BRAIT, B. (Org.) Bakhtin: outros conceitos-chave. São Paulo: Contexto, 2010, p. 95-113.

BAKHTIN, M. Os gêneros do discurso. In: Estética da criação verbal. Trad. Paulo

Bezerra. 4. ed. São Paulo: Martins Fontes, 2006.

BAKHTIN, M. Para uma filosofia do ato responsável. Trad. aos cuidados de Valdemir Miotello \& Carlos Alberto Faraco. 2. ed. São Carlos: Pedro \& João Editores, 2010.

Problemas da poética de Dostoievski. Trad. Paulo Bezerra. 5. ed. Rio de Janeiro: Forense Universitária, 2013.

BAKHTIN, M. (VOLOCHINOV) (1929). Marxismo e filosofia da linguagem. Trad. Michel Lahud e Yara Frateschi Vieira. 11. ed. São Paulo: Hucitec, 2004.

BRAIT, B. Análise e teoria do discurso. In: (Org.). Bakhtin: outros conceitos-chave. São Paulo: Contexto, 2010.

Construção coletiva da perspectiva dialógica: história e alcance teórico-metodológico. In: FIGARO, R. (Org.). Comunicação e análise do discurso. São Paulo: Contexto, 2013, p. 79-98.

BRAMMERTS, H. Tandem language learning via the internet and the International E-Mail Tandem Network. In: LITTLE, D.; BRAMMERTS, H. (Eds.). A Guide to Language Learning in Tandem via the Internet. CLCS Occasional Paper, 46, 1996, p. 9-22. 
DOOLY, M.; O'DOWD, R. Researching online foreign language interaction and exchange: theories, methods and challenges. Peter Lang Publishing. (Telecollaboration in Education Volume 3), 2012.

FIORIN, J. L. Categorias de análise em Bakhtin. In: PAULA, L. de; STAFUZZA, G. (Org.). Círculo de Bakhtin: diálogos (in)possíveis. Volume 2. Série Bakhtin - Inclassificável. Campinas, SP: Mercado de Letras, 2011, p. 33-48.

FRANCO, G. R. Aspectos linguisticos emergentes em sessões de teletandem: uma análise a partir da conscientização da linguagem. 2016. 172 f. Dissertação (Mestrado em Estudos Linguísticos em elaboração) - Instituto de Biociências, Letras e Ciências Exatas, Universidade Estadual Paulista, São José do Rio Preto, 2016.

KRAMSCH, C. Third Culture and Language Education. In: WEI, L.; COOK, V. (Eds.) Contemporary Applied Linguistics: Volume One Language Teaching and Learning. London: Continuum International Publishing Group, 2009. Disponível em: < http://lrc.cornell.edu/events/past/2008-2009/papers08/third.pdf > . Acesso em: 17 fev. 2014.

MARINOTO, D. N. Teletandem: o dominio ideológico nas sessões orais online entre aprendizes de línguas estrangeiras. 2017. 137 f. Dissertação (Mestrado em Estudos Linguísticos) - Instituto de Biociências, Letras e Ciências Exatas, Universidade Estadual Paulista, São José do Rio Preto, 2017.

O'DOWD, R. Intercultural communicative competence through telecollaboration. In: JACKSON, J. (Ed.). The Routledge Handbook of Language and Intercultural Communication, New York: Routledge, 2011, p. 342-358.

PAULA, L. de. Círculo de Bakhtin: uma Análise Dialógica de Discurso. Revista de Estudos da Linguagem, Belo Horizonte, v. 21, n. 1, p. 239-258, jan./jun. 2013.

SOUZA, M. G. Teletandem e mal-entendidos na comunicação intercultural online em língua estrangeira. Tese de Doutorado. P.P.G. em Estudos Linguísticos, UNESP- Universidade Estadual Paulista, 2016.

TELLES, J.A. Projeto Teletandem Brasil: Línguas Estrangeiras para Todos - Ensinando e Aprendendo línguas estrangeiras in-tandem via MSN Messenger. Faculdade de Ciências e Letras de Assis, UNESP. 2006.2 Disponível em: $<$ http://www.teletandembrasil.org/site/docs/TELETANDEM_BRASIL_completo.pdf $>$. Acesso em: 02 set. 2010.

Teletandem e Transculturalidade na interação on-line em línguas estrangeiras por webcam. Projeto de pesquisa financiado pela FAPESP, 2011.

TELLES, J. A.; VASSALLO, M. L. Foreign language learning in-tandem: Teletandem as an alternative proposal in CALLT. The ESPecialist, v. 27, n. 2, p. 189-212, 2006.

- Teletandem: Uma proposta alternativa no ensino/aprendizagem assistidos por computadores. In: TELLES, J.A. (Org.). Teletandem: Um contexto virtual, autônomo e colaborativo para aprendizagem de línguas estrangeiras no século XXI. Campinas, SP: Pontes Editores, 2009, p. 43-61. 
ZAKIR, M. A. Cultura e(m) telecolaboração: uma análise de parcerias de teletandem institucional. 2015. 232 f. Tese (Doutorado em Estudos Linguísticos) - Instituto de Biociências, Letras e Ciências Exatas, Universidade Estadual Paulista, São José do Rio Preto, 2015. Disponível em: < http://www.teletandembrasil.org/site/docs/ZAKIR2015.pdf>. Acesso em: 05 out. 2015.

Submetido em $01 / 12 / 2018$

Aceito em 23/04/2019

Publicado em 18/06/2019 